\title{
Gestação e tabagismo: representações e experiências de pacientes de Unidades de Saúde da Família
}

\author{
Pregnancy and smoking: representations and \\ experiences of patients of Family Health Units \\ Bruno José Barcellos Fontanella', Karina Nogueira Dias Secco²
}

\section{RESUMO}

Objetivo: Analisar e interpretar o que gestantes dependentes de tabaco/nicotina pensam e experimentam quanto à problemática relacionada a essas condições. Método: Pesquisa qualitativa utilizando narrativas de gestantes ou puérperas que fumaram ou interromperam o uso de tabaco na gestação. As narrativas de uma amostra intencional de 14 usuárias de Unidades de Saúde da Família de um município paulista foram analisadas quanto aos enunciados. Resultados: Formularam-se quatro categorias: contraste entre desejo de interromper o uso e o papel não identificado dos profissionais e serviços; questões sobre a saúde da mãe e da criança; questões socioculturais e familiares e, por fim, uma "epidemiologia espontânea". As representações sociais constatadas mostram discrepâncias e homologias com os modos como as ciências da saúde lidam com o tabagismo no período gestacional. As participantes consideraram inexistir uma cultura terapêutica para tabagismo nos serviços de Atenção Pri-

\section{Palavras-chave}

Unidades de Saúde da Família, tabagismo, gestação, pesquisa qualitativa. mária à Saúde que frequentam, tendo se mostrado angustiadas com essa questão e com os conflitos socioculturais e familiares que enfrentam. Uma compreensão peculiar sobre os riscos para a saúde foi constatada. Conclusão: Embora os resultados não sejam generalizáveis, as tensões constatadas sugerem caminhos para uma maior adaptação da Atenção Primária à Saúde às necessidades das gestantes tabagistas.

\section{ABSTRACT}

Objective: To analyze and deepen understanding about what pregnant women who are tobacco/nicotine dependents think and experience about these conditions. Method: Qualitative research using narratives obtained from a purposive sample of pregnant or puerperal smokers or who discontinued tobacco use during pregnancy. The narratives' statements of fourteen patients from Family Health Units of a Brazilian municipality were analyzed. Results: Four categories were formulated: the desire to stop using, contrasting with the unidentified role professionals and services; questions about the health of the mother and her child; sociocultural and family issues and, finally, what is termed here as "spontaneous epidemiology". Social representations that were observed show discrepancies and homologies with the ways in which health sciences deal with smoking during pregnancy. The participants

1 Universidade Federal de São Carlos (UFSCar), Departamento de Medicina, Centro de Ciências Biológicas e da Saúde (CCBS), Área de Saúde Mental. 2 UFSCar-CCBS.

Endereço para correspondência: Bruno José Barcellos Fontanella Departamento de Medicina - CCBS-UFSCar Rod. Washington Luís, km 235 13565-905 - São Carlos, SP Telefones: (16) 3351-8340 e (19) 9221-4439

E-mail: bruno.fontanella@gmail.com 


\section{Keywords}

Family Health Units, smoking, pregnancy, qualitative research. considered not to exist a therapeutic culture for nicotine dependence in Primary Health Care services they frequent, and they seemed to be distressed about this issue as well with the socio-cultural and family conflicts they face. A peculiar understanding about the health risks came to light. Conclusion: Although the results are not generalizable, the tensions observed strongly suggest the need for further adaptation of the Primary Health Care to the needs of pregnant smokers.

\section{INTRODUÇÃO}

São ainda pouco conhecidos vários dos fenômenos envolvidos na relação entre gestação e tabagismo, apesar de esses problemas há muito se configurarem como relevantes no cotidiano clínico dos psiquiatras, clínicos-gerais, obstetras e sanitaristas.

Em 2004, a Organização Mundial da Saúde (OMS) estimava que $12 \%$ da população mundial de mulheres adultas eram fumantes. Países desenvolvidos e em desenvolvimento se encontram em diferentes estágios da epidemia de tabagismo, isso se refletindo no coeficiente de prevalência entre as mulheres nesses contextos geográficos: $7 \%$ e $24 \%$, respectivamente ${ }^{1,2}$. No Brasil, estudos realizados na última década ${ }^{3,4}$ estimaram que, para as faixas etárias correspondentes à maior fertilidade feminina (18-24 e 25-34 anos), os coeficientes de prevalência de uso na vida de tabaco foram respectivamente de $32,6 \%$ e $36,1 \%$ (em 2001) e 33,9\% e 35,7\% (em 2005). Para essas mesmas faixas etárias e sexo, os coeficientes de prevalência de dependência de tabaco foram respectivamente 6,8\% e 9,3\% (em 2001) e 9,4\% e 7,2\% (em 2005).

A política brasileira para a Atenção Primária à Saúde (APS) tem recomendado medidas preventivas para o tabagismo que incluem aumentar o acesso dos pacientes a métodos eficazes para cessação do uso ${ }^{5}$. Os consensos recomendam que as gestantes e nutrizes fumantes, para quem o instrumental terapêutico é mais limitado, devem ter acesso a uma abordagem psicoterápica cognitivo-comportamental ${ }^{6,7}$. Recomendam também que os profissionais da APS estejam preparados para abordar os tabagistas e motivá-los a interromper o uso ${ }^{6}$.

Em qualquer fase do ciclo vital e para qualquer sexo, a cessação do uso do tabaco promove benefícios à saúde, sobretudo diminuindo riscos cardiovasculares e de alguns cânceres. Entre as gestantes, os benefícios são ainda maiores, haja vista que o hábito tabágico leva a riscos adicionais para a mulher, seu concepto e para o recém-nascido, associando-se a um risco maior de aborto, placenta prévia, ruptura prematura das membranas, descolamento prematuro de placenta, gravidez tubária ${ }^{8,9}$, nascimentos pré-termo, baixo peso ao nascer, defeitos congênitos e maior risco de alergias e infecções para a criança ${ }^{10}$.

Já se constatou que, em alguns contextos geográficos e assistenciais brasileiros, a maioria das gestantes já estaria informada sobre alguns desses problemas de saúde relacio- nados ao uso de tabaco ${ }^{11}$. Mesmo que a maior parte continue usando durante a gestação, cerca de $20 \%$ interrompem espontaneamente o uso no período que vai do início da gestação até o momento do parto ${ }^{12,13}$, o que é uma taxa substancialmente maior do que o abandono espontâneo em mulheres não gestantes ${ }^{8}$. Os fatores relacionados a essa interrupção espontânea são apenas supostos ${ }^{13}$, parecendo relacionar-se a maior escolaridade, ter parceiro fixo, ter tido uma gravidez planejada e ter experimentado náuseas durante o primeiro trimestre de gestação ${ }^{12,14}$. Parcela significativa das mulheres que interrompem volta a fumar após o parto.

Em vista do até aqui exposto, considera-se que o que está em jogo na continuação ou na interrupção do uso de tabaco nesse período de gestação configura-se como uma instigante questão científica, tanto em razão das lacunas de conhecimento existentes quanto em função dos benefícios que o melhor entendimento dessa problemática pode trazer.

Dada a grande heterogeneidade cultural da população brasileira, estudos que utilizem métodos qualitativos (ou compreensivo-interpretativos) podem ajudar a esclarecer aspectos dessa problemática. Além de fornecer subsídios para pesquisas clínicas e epidemiológicas, esses estudos podem aumentar o repertório de atuação dos profissionais envolvidos nesse tipo de cuidado e, também, influenciar a política de saúde pública. No contexto nacional, no entanto, permanecem cientificamente pouco exploradas as perspectivas das próprias gestantes sobre o hábito de fumar.

Recentemente, iniciou-se no Brasil uma discussão sobre a questão do tabagismo feminino, de modo geral, estudado sob a ótica qualitativa crítica das relações de gênero ${ }^{15,16}$, instigando o debate sobre o tema. Entretanto, estudos qualitativos específicos sobre tabagismo na gestação permanecem $\operatorname{raros}^{17}$.

Com o intuito de contribuir para essa discussão, nesta presente investigação formulou-se a seguinte questão: que tipo de vivências as gestantes ou puérperas tabagistas usuárias da APS (em Unidades de Saúde da Família - USF) relatam com relação a esse comportamento? O objetivo foi coletar e analisar suas narrativas sobre o tema, procurando compreender os significados que conformam as experiências e representações das gestantes. Para este trabalho interpretativo, foram utilizados alguns referenciais das ciências sociais em saúde ${ }^{18,19}$, tendo a discussão também se beneficiado da perspectiva de gênero quanto ao tabagismo feminino ${ }^{15,16} \mathrm{e}$ também da psicologia social no campo da saúde ${ }^{17,20,21}$. 


\section{MÉTODO}

Foi utilizada uma abordagem qualitativa sobre um conjunto de narrativas orais, obtidas por meio de entrevistas individuais semidirigidas com questões abertas ${ }^{22}$ com mulheres frequentadoras dos serviços públicos de APS/USF do município de São Carlos (SP). Os critérios de inclusão de participantes foram: (a) ser gestante ou estar no puerpério; (b) fumar tabaco diariamente ou ter fumado durante a gestação (mesmo que tenham interrompido) e (c) encontrar-se em condições para participar das entrevistas (do ponto de vista emocional, intelectual e físico). A execução do projeto foi autorizada pelo Comitê de Ética em Pesquisa com Seres Humanos da universidade e as participantes assinaram o termo de consentimento livre e esclarecido aprovado por esse comitê, depois de contatadas nas USF às quais a estudante tinha acesso como estudante de medicina.

As entrevistas narrativas, realizadas em local de escolha das entrevistadas (em suas casas ou nas USF que frequentavam), foram utilizadas porque se propõem a revelar os acontecimentos vividos pelos agentes sociais a partir de suas próprias perspectivas, possibilitando que as ações e os contextos narrados mostrem "o lugar, o tempo, a motivação e as orientações do sistema simbólico do ator"23 (p. 93). Tendo a gravação de áudio sido autorizada pelas entrevistadas, o tema principal foi proposto às participantes (Quadro 1), com as devidas adaptações de vocabulário aos seus universos socioculturais e educacionais. A entrevistadora (KNDS) procurou estar atenta à delicadeza com que a temática devia ser colocada, de modo a dirimir o risco de danos psicológicos ao abordar um assunto que poderia ser emocionalmente difícil para as entrevistadas. Ademais, procurou catalisar a expressão das participantes e estimular suas reflexões.

Quadro 1. Temário utilizado nas entrevistas

\begin{tabular}{l}
\hline Tema principal: \\
\hline $\begin{array}{l}\text { - suas reflexões sobre o fato de estar fumando ou ter parado de fumar durante a } \\
\text { gravidez }\end{array}$ \\
\hline Subtemas: \\
\hline - motivos percebidos para ter continuado a fumar ou ter parado de fumar durante a \\
gravidez \\
- percepções de coerções sociais e médicas ao fato de fumar durante a gravidez \\
- expectativas quanto a voltar a fumar depois da gravidez
\end{tabular}

Depois de transcritas, as narrativas passaram por um processo de análise de enunciação ${ }^{24}$ que procurou valorizar, além das expressões manifestas, dois processos de elaboração e transformação de sentidos. Por um lado, a análise procurou considerar as dinâmicas psicológicas das participantes perante a problemática que vivenciavam (tabagismo durante a gestação). Por outro lado, procurou também estar atenta às questões da dinâmica sociocultural, inclusive ao contraponto entre os saberes do senso comum e os saberes médicos técnico-científicos ${ }^{18,19,21}$.
Utilizou-se um processo de amostragem intencional fechado por saturação, ou seja, interrompendo a coleta de novas narrativas quando se supôs dispor de elementos empíricos suficientes para um aprofundamento da discussão e ao se perceber não mais surgirem novos tipos de enunciados ${ }^{25,26}$. Nesse tipo de amostragem, não há pretensões de generalização estatística dos resultados.

\section{RESULTADOS}

As 14 entrevistas foram realizadas entre agosto de 2008 e junho de 2009. Procurando contextualizá-las, o quadro 2 resume algumas características sociodemográficas e clínicas do grupo de participantes. As participantes foram identificadas pelos números de 1 a 14.

Os tipos de enunciados foram reunidos em quatro categorias de resultados, expostas a seguir, tendo sido feita uma seleção de enunciados que as fundamentam (Quadros 3 a 6). Na seção seguinte, essas categorias são discutidas.

Quadro 2. Perfil sociodemográfico das participantes $(N=14)$

\begin{tabular}{|c|c|}
\hline & $\mathrm{N}$ \\
\hline \multicolumn{2}{|l|}{ Estado civil } \\
\hline Solteira & 7 \\
\hline Casada & 7 \\
\hline \multicolumn{2}{|l|}{ Escolaridade } \\
\hline $0-4$ anos & 3 \\
\hline $5-8$ anos & 7 \\
\hline$>8$ anos & 4 \\
\hline Idade & 16 a 40 anos (média $=26,6$ anos) \\
\hline \multicolumn{2}{|l|}{ Momento da entrevista } \\
\hline Durante a gestação & 9 \\
\hline No puerpério & 5 \\
\hline \multicolumn{2}{|l|}{ Tabagismo durante a gestação } \\
\hline Interrompeu espontaneamente & 2 \\
\hline Diminuiu espontaneamente & 2 \\
\hline Interrompeu sob orientação & 1 \\
\hline Diminuiu sob orientação & 3 \\
\hline Manteve mesmo padrão & 6 \\
\hline \multicolumn{2}{|l|}{ Atividade econômica } \\
\hline Empregada doméstica & 1 \\
\hline Atendente de bar & 1 \\
\hline Babá & 1 \\
\hline Auxiliar de limpeza & 1 \\
\hline Cuidadora de idosos & 1 \\
\hline \multicolumn{2}{|l|}{ Não tem } \\
\hline \multicolumn{2}{|l|}{ Religiäo } \\
\hline Católica & 8 \\
\hline Evangélica & 3 \\
\hline Não tem & 3 \\
\hline
\end{tabular}


Quadro 3. Exemplos de enunciados das entrevistadas relacionados ao desejo de interromper o uso e o papel (não identificado) da APS

"Falei: 'agora além de ser bom para minha saúde é bom para a saúde do nenê [...] Com a gravidez, foi mil por cento, uma consciência a mais para parar e que pesou sobre mim. [...] Acontece de passar nervoso, daí é onde que [o cigarro] parece que alivia a tensão." [1]

"Gostaria muito de parar. Nunca tentei fazer nada pra parar... já pensei assim, futuramente, em parar..." [...] [A medicina] é tão adiantada, por que não inventa um remédio para a pessoa tomar nojo de cigarro?" [2]

"Cigarro num copo de água foi uma tentativa, mas já tiveram as outras também. [...] Às vezes acaba passando algum tipo de nervoso, você acaba lembrando." [3]

"Queria que existisse [um tratamento] apesar de que tem uma pastilha com gosto de nicotina, que a pessoa chupa e então parece que está alimentando, por causa do gosto da nicotina que tem na bala, mas nunca tentei experimentar, porque diz que é muito caro. [...] [A médica] falou que era pra parar porque faz mal pro nenê. Falaram isso. [...] A única coisa que tenho medo de fazer é tirar um raio $x$ do pulmão. Não adianta nem médico pedir porque não faço. Passa na televisão alguma pesquisa falando de como o pulmão fica, desligo, ignoro, porque não quero saber de que jeito que está dentro de mim. Se tiver que morrer, quero morrer sem saber nada." [4]

"Consegui parar de fumar porque me dava enjoo, vontade de vomitar. Depois que fui inteirando meus três, quatro meses, aí fui tentar de novo e não deu mais enjoo. Aí voltei a fumar de novo." [5]

"Aí a médica falou assim que era perigoso causar problema, aí resolvi parar. Hoje parei e não tenho mais nem vontade. [...] Me mostrou fotos do que podia acontecer [...] de umas crianças... que podia morrer, nascer com problemas... [...] bebezinhos no vidrinho... [...] Aí fumava 20 cigarros por dia, depois fumei 5, 3 depois... parei." [6]

"Agora surgiu o cigarro eletrônico. Não tem nicotina, ele vem em um maço e é vapor de água que sai." [...] [0 médico] não falou muita coisa." [7]

"...a gravidez como um bom motivo para parar [...] queria, mas não tinha forças. [...] Nem com filho eu consegui. Não dá [...] falta força de vontade, essa é a palavra certa. [...] Pega a água, 0 cigarro, põe lá dentro com tudo, toda a nicotina lá e deixa a noite inteira. Fica tudo amarelo. A mãe falou: 'toma que daí você vai ficar com nojo' Aí tomei [...] Aí que comecei a gostar mais ainda (risos)." [8]

"Mandou parar mesmo porque não era bom pro nenê, e por causa da minha bronquite também, complica mais ainda para a criança. Mas também ela falou isso daí... me deu esses conselhos só umas duas vezes, depois o resto... [...] Pretendo mesmo parar [...] então já diminuí bastante... Por mais que a gente lave a mão o cheiro sempre fica, da nicotina, sempre fica nos dedos. E a gente tá pegando [...] no colo para amamentar, para parar de chorar e passa o cheiro para ela, também. Então pretendo já parar mesmo." [9]

"Falou que era para mim parar. [...] para fazer um esforço para parar, que fazia mal para 0 nenê e para mim também, mas mesmo assim não adianta... [...] Mas dizem que o fumo [de corda] não faz tão mal quanto o cigarro, por causa da nicotina." [10]

"Ah, não é que tem uns remédios para parar de fumar? [...] vejo na televisão, ouço as pessoas comentarem..." [11]

"Não perguntou nem se fumava... e não falei também... [...] Agora na gravidez o cigarro me dá enjoo, então vou mais de fumo [de corda] mesmo." [12]

"Tem atrás do maço de cigarro brasileiro aquelas advertências. [...] É ver só por ver, porque ajudar não ajuda. Vi também um cartaz sobre uma igreja que está ajudando o pessoal a parar." [14]

Quadro 4. Exemplos de enunciados das entrevistadas relacionados à saúde da mãe, do embrião, do feto e do bebê

"Dentro da casa não pode porque eles [os pais] são de idade." [2]

"Às vezes vem aquelas fotinhos ilustradas no cigarro e você não quer acreditar, tampa, vira, não quer enxergar... [...] Quando as minhas meninas nasceram, não fumava dentro de casa, só da porta da cozinha pra fora, no quarto não. [Quando] elas estavam com uma idade bem mais avançada, já 2, 3 anos, 4 aninhos, você vê que ela já não fica tão fraca..." [3]

"Não nascer algumas partes do corpo [...] 0 cérebro desenvolver bem mais devagar, 0 bebê pode nascer com asma. A nicotina já vai estar no sangue dele, vai ser mais provável ele ser um fumante quando crescer, porque já vai ter nicotina no sangue, vai sentir o cheiro e vai gostar. Uma amiga tem asma, às vezes tem que usar aparelhinho porque a mãe dela fumou muito na gravidez." [8]

"Fumo fora de casa, daí depois escovo meus dentes, lavo a minha mão, mas agora me falaram lá em cima que não adianta nada [para proteger 0 bebê], porque o cheiro fica na roupa..." [12]
Quadro 5. Exemplos de enunciados das entrevistadas relacionados a questões de suas vidas sociocultural e familiar

"A população acha que a criança foi gerada porque foi maus-tratos da mãe que fumava ou que bebia, então acho que tem muito preconceito." [1]

"Ele [marido] acaba de almoçar, nem fuma um inteiro e vai dormir. Ele acorda, tira um traguinho de novo, apaga, daí ele vai se arrumar pra trabalhar. Ele pega muito no pé. [...] Foi na roda de amiguinhas [que comecei]. As amiguinhas tudo com cigarrinho na mão, com copinho de cerveja e fui pegando o embalo: 'me dá um trago pra ver como é que é?' E elas davam, aí viciei mesmo. Não sei... por boniteza talvez, por curiosidade de estar fumando. Aquela coisa muito interessante... [...] Meu pai fumava, minha mãe, a minha irmã mais velha, o marido dela... Aquele tempo lá no sítio, não lembro se tinha cigarro, era aqueles fumos. 0 meu pai que ensinou ela [irmã] a fumar. Ele fazia o palheiro para ele e fazia para ela também. [2]

“Fala: 'olha, ela tá prejudicando o nenê, não parou de fumar...' [...] Tem um preconceito muito grande. Porque se a mulher fuma sem tá grávida, que se dane. Se tá grávida, elas pensam: 'ah, o que a criança tem a ver?' 0 preconceito maior é fumar grávida." [7]

"Só quem fumava era minha tia. Com o tempo, esse negócio 'filha, vai lá e ascende 0 cigarro pra tia"' [10]

"Tem gente que fala: "olha lá, a louca fumando grávida!" [12]

Quadro 6. Exemplos de enunciados das entrevistadas relacionados a seus conhecimentos espontâneos de epidemiologia e risco

"Eles falam que é bom para a gente..." [1]

"Uma amiga que na gravidez até maconha fumava e os filhinhos dela nasceram tudo bem. Acho que é Deus que protege nessa parte... [...] Não conseguia mesmo fumar e ele nasceu tão fraquinho!" [2]

"Tem aquele ditado, que você não crê, mas também não desacredita... Porque nunca vi nada [consequências nocivas do cigarro para os bebês], então..." [3]

"Tiro essa noção por mim. Bom, não aconteceu nada com minhas outras gravidezes, não vai acontecer com essa também." (4)

"Ah, [0 cigarro] faz muita coisa... mal de enfarte.. mas eu tenho muita fé em Deus." [10]

"Acho que não é comum... porque do meu segundo filho também fumei na gravidez e graças a Deus ele não teve nada e já está com 6 anos." [12]

"Acho que é o seguinte [...] mal não faz porque, veja bem, tenho aí um montão [tem seis filhos] e fumei em todas e eles tão tudo aí." [13]

"Conheço [quem fumou na gestação]. Nasceram bem, mais saudável que a minha! (risos)" [14]

\section{Desejo de interromper o uso e o papel (não identificado) da APS}

No quadro 3, são exemplificados alguns enunciados proferidos durante as entrevistas e que ajudam a fundamentar empiricamente as observações que se seguem.

As entrevistadas, de modo geral, expressaram desejar interromper o uso do tabaco. Mesmo que não tenha havido unanimidade quanto a esse propósito ("não tentei nem pretendo" - entrevistada 14), a gestação foi considerada um "bom motivo" para parar.

A despeito da explicitação comum desse desejo, não foram expressas demandas formalizadas por tratamento, em qualquer área de cuidado formal. Situaram o problema de interromper o uso como algo que deve ser enfrentado isoladamente pela gestante.

Não houve manifestações de conhecerem ou crerem na efetividade de tratamentos para tabagismo e, segundo uma delas, a medicina como que deve uma resposta para o problema. 
Além de não terem formulado demandas, nenhuma das informantes sequer cogitou a possibilidade de ajuda profissional para o hábito tabágico; o sistema de saúde pareceu ser percebido como algo com o que não poderiam contar para essa finalidade.

As infrequentes menções às possibilidades terapêuticas existentes foram feitas de modo apenas tangencial, referidas como recomendadas fora do sistema formal de saúde. Uma das entrevistadas verbalizou que a medicina produziria remédios que "cortam" os problemas, porém não para o tabagismo; duas outras assinalaram haver técnicas terapêuticas, porém inacessíveis ou mirabolantes.

Quando relataram ter recebido orientações profissionais, tais iniciativas pareceram ser avaliadas como genéricas, limitadas a informações sobre malefícios para a saúde. Médicos e outros profissionais foram por vezes considerados ausentes ou dando orientações apenas pontuais.

Houve um relato de um profissional fazer recomendações demoradas e recomendar a redução de número de cigarros. Parece ter utilizado técnicas cognitivo-comportamentais aversivas, porém aparentemente não sistematizadas numa proposta ou planejamento terapêutico que tenha sido compreensível pela paciente (entrevistada 6).

Uma entrevistada (entrevistada 4) expressou medo dos recursos utilizados pela medicina para avaliar o efeito do uso do tabaco.

Não percebendo como poderiam demandar tratamento, algumas participantes mantiveram o uso inalterado; outras procuraram postergar a resolução desse conflito, fazendo planos de interromper somente depois do parto; outras se utilizaram de uma lógica espontânea e informal de redução de danos ${ }^{27}$, por exemplo, diminuindo a quantidade ou usando o fumo de corda, considerado por uma delas (entrevistada 10) como menos prejudicial, por provocar menos enjoo.

Houve relatos de tentativas por vezes reiteradas de interrupção sem supervisão profissional, incluindo autotratamentos ("simpatias"), técnicas comportamentais autoinstituídas e menções a recursos fora do sistema formal de saúde (entrevistadas 3, 4, 8 e 14).

Uma entrevistada referiu ter interrompido o uso "assim que soube" da gestação e uma outra interrompeu depois de "levar susto" relacionado à saúde do feto. Uma paciente relatou ter parado temporariamente. O ganho de peso e o alívio de tensão/ansiedade associados ao uso do tabaco ("um calmante") foram citados como fatores que desmotivam a interrupção (entrevistadas 1 e 3).

Observe-se, por fim, particularmente no quadro 6, que a palavra "nicotina" foi usada de modos variados e, geralmente, não correspondendo ao conceito farmacológico científico (entrevistadas 4, 7, 8, 9 e 10).

\section{A saúde da mãe, do embrião, do feto e do bebê}

Como esperado pelas circunstâncias da pesquisa, o tema saúde foi valorizado pelas entrevistadas, sendo um aparente gerador de intenso sofrimento emocional. O quadro 4 exemplifica enunciados desse tipo.

Foram constatadas entre as participantes algumas compreensões bastante peculiares sobre a relação entre tabagismo, saúde e doenças, e a maneira como os possíveis danos para o embrião e para feto foram descritos pode ou não corresponder aos atuais conhecimentos médicos sobre o tema (por exemplo, os enunciados das entrevistas 8 e 12, no quadro 4).

A gestação foi vista como uma situação que "altera tudo" (entrevistada 1) no corpo da mãe e, caso associada ao tabagismo, geraria sintomas e problemas adicionais: "faz mal" (1), prejudicaria os pulmões (13), causaria "mal-estar" e "azia" (10), "falta de fôlego" (6) - danos esses avaliados como proporcionais à quantidade de cigarros consumida, o que talvez se associe às medidas de redução do número de cigarros por algumas participantes.

Ser adulta (o que coincide com a idade fértil) foi também percebido como uma fase de menor vulnerabilidade a esses problemas - ao contrário dos idosos e bebês, tidos como mais vulneráveis (enunciados de 2 e 3 ).

Interromper o tabagismo foi então considerado como algo bom para o bebê e ajudaria a evitar alguns problemas: danos intraútero ao pulmão; o feto não cresceria e não se desenvolveria; teria baixo peso; haveria danos à circulação do bebê e "pouco oxigênio"; prematuridade seria possível; levaria a problemas respiratórios para o recém-nascido (asma, bronquite); o coração do bebê ficaria mais "rápido" e ele ficaria mais "agitado".

\section{A gestante tabagista e sua vida sociocultural e familiar}

Como exemplificado no quadro 5, as entrevistadas no geral pareceram perceber-se como alvos de discriminações e considerar haver uma atribuição social de culpa às mães tabagistas. Observe-se que na frase da entrevistada 2 há uma menção a um uso de tabaco por seu esposo de forma aparentemente mais ritualizada e, por ser aparentemente menos compulsivo, esse uso parece ser considerado menos grave por ela.

As entrevistadas em geral se desenvolveram em ambientes familiares em que fumar tabaco era prática comum e tacitamente aceita, tendo sido observados relatos de possíveis conflitos entre os diferentes valores culturais das famílias de origem (pais e irmãos) e da atual família nuclear (esposo e filhos). As atuais posturas familiares foram percebidas simultaneamente ora como sancionando o uso, ora como mais compreensivas ("não fica pegando no meu pé" - 3). Pressões familiares do cônjuge, filhos e mães foram comentadas como exacerbadas no período gestacional.

Outros variados elementos familiares e socioculturais relacionados ao tabagismo foram mencionados: posturas moralistas ("ia ter que sustentar meu vício" - 10 e 13); histórias 
de frustrações "orais" explicando o atual tabagismo (famílias que passaram fome); trabalho infantil, migração e baixa escolaridade expondo ao tabagismo.

Houve também menções a um certo de exercício de feminilidade relacionado ao tabagismo, envolvendo aspirações estéticas, questões de grupalidade feminina e aprendizado de padrões comportamentais femininos que incluíam o tabagismo (por exemplo, entrevistadas 2 e 10).

\section{Epidemiologia espontânea}

O quadro 6 fornece exemplos de enunciados dessa categoria.

Os possíveis danos e problemas para o feto e para o bebê foram, para algumas entrevistadas, permeados por ideias de um poder protetor divino. Ocorreriam ou não, segundo uma lógica compreendida nessa dimensão (entrevistadas 2 e 10).

Houve menção a ser a dependência de nicotina algo hereditário ou mesmo congênito: a mãe fumante durante a gestação aumentaria a chance de o bebê ser fumante no futuro, em razão de habituação com a nicotina (ver excerto da entrevista 8).

Como essas, foi também chamativa nas narrativas a presença de outras noções espontâneas de epidemiologia. Parece haver, de modo geral, uma compreensão muito peculiar da noção epidemiológica de risco. Algumas entrevistadas recorreram a uma espécie de casuística própria, a partir da qual tiraram conclusões para fundamentar suas decisões (3, 4, 12 e 13, por exemplo).

Houve referências a histórias pessoais de gestações anteriores "tranquilas", mesmo fumando, e de terem, ao contrário, observado pessoas próximas não fumantes que deram à luz crianças com baixo peso (2 e 14).

Observaram-se, ainda, interessantes menções às ciências médicas e a seus representantes (os profissionais de saúde) como sujeitos indeterminados, que "sabem" os malefícios do cigarro, ao contrário das pessoas leigas, que desconheceriam detalhes (entrevistada 1).

\section{DISCUSSÃO}

As questões acima explicitadas exemplificam alguns dos sentidos culturais e psicológicos que pacientes gestantes tabagistas podem ter dessa complexa condição. O mesmo corpus de narrativas poderia certamente ser analisado de modo diferente por outros autores, em razão da polissemia intrínseca dos objetos estudados pelas ciências humanas.

Alguns enunciados foram lidos como situados na esfera dos saberes coletivos, isto é, como representações sociais e valores culturais relacionados ao tabagismo, à atenção formal à saúde, à gestação e à feminilidade. Outros conteúdos se configuram claramente, na visão dos autores, como mecanismos de defesa psíquicos, portanto mais na esfera individual.
Observe-se, entretanto, que os conflitos subjacentes a esses mecanismos defensivos parecem, entre as mulheres participantes, envolver típicos elementos de uma aguda problemática de gênero, atravessada por igualmente agudas questões de classe social15,16. Como se infere a partir do quadro 2, a amostra estudada foi composta por mulheres com um claro perfil de baixa escolaridade e de não inserção (ou inserção precária) no mercado de trabalho, figurando-se, então, como típica da tendência da problemática atual do tabagismo, associando feminização e pauperização dessa condição ${ }^{16}$.

\section{Representações sociais: os exemplos da "nicotina" e do "risco"}

O uso do termo "nicotina", pelas participantes, pode ser um exemplo da influência dos conhecimentos reificados (próprios da medicina e de outras áreas da saúde), sobre as representações sociais do que é ser uma fumante. Algumas entrevistadas utilizaram essa palavra com nítidas discrepâncias em relação ao seu significado farmacológico. Embora seja esperado que a dinâmica da passagem do conhecimento técnico-científico para o público em geral se faça sob forte influência de outros tipos de conhecimento ${ }^{20}$, chamou a atenção, neste caso, que a utilização do termo "nicotina" nas narrativas constituiu-se numa apropriação praticamente não semântica desse léxico, tendo as entrevistadas somente uma noção vaga de que, nos cigarros de tabaco que fumam, há coisas que desconhecem, são perigosas e que denominam "nicotina". De modo geral, a lógica do conhecimento médico parece ser vista como hermética e inacessível a uma compreensão mais organizada pelas participantes, lógica essa estranha às suas experiências cotidianas, mas que Ihes impõe inclusive sua linguagem, como já teorizado décadas atrás ${ }^{18}$.

As entrevistadas verbalizaram que o período gestacional seria o momento propício e oportuno para alterar o hábito tabágico, nesse sentido indo ao encontro da opinião médica vigente ${ }^{8}$. Isso pareceu decorrer, sobretudo, do medo de danos para o feto e para o bebê, danos esses também compreendidos por elas de modo peculiar e diferente do das ciências da saúde, o que ratifica achados de pesquisas anteriores sobre representações sociais sobre esses possíveis malefícios ${ }^{17}$. Para as participantes, essa possibilidade de danos situou-se aparentemente num plano mais difuso de compreensão, que mesclou saberes de ordem moral e mística.

A noção de "risco para adoecer" parece ser apropriada de modo bastante próprio pelas informantes, contrastando com sua utilização no discurso dos profissionais de saúde e no marketing contra o tabagismo. Tratando-se o "risco" de um conhecimento matemático, utilizado ao seu modo pelas ciências médicas, essa noção não parece se difundir com facilidade para $\mathrm{O}$ universo consensual ${ }^{20}$ dessas pacientes, gerando, então, representações sobre "risco" que se contrapõem à noção utilizada na clínica e criando, possivelmente, 
tensões no encontro dessas mulheres com seus cuidadores formais. Há, aparentemente, dificuldades de compreensão do que sejam "fatores de risco" para a saúde da mãe e do bebê, tendo as entrevistadas utilizado em seus raciocínios uma "casuística" própria e noções epidemiológicas que poderiam ser denominadas de "espontâneas", fenômeno próximo e paralelo à "nosografia popular"18 e à "etiologia leiga"19, também decorrentes das tensões entre os saberes médicos e os do público geral.

\section{Conflitos, angústias e "soluções" das entrevistadas}

Consideramos compreensível, do ponto de vista psicocultural, que tenham sido expressos com frequência, pelas participantes, raciocínios que valorizaram os mencionados discursos de ordem moral e mística. A problemática representada pela associação gestação-tabagismo traria à tona, de forma aguda, várias questões culturais e morais coletivas relacionadas à maternidade, à responsabilização sobre o outro, em particular sobre os filhos, e à ideia de culpa por algo percebido como um descontrole pessoal, como o ver-se dependente de uma substância psicoativa. Na ausência de acesso a recursos terapêuticos para lidar com o problema, essas mulheres recorreriam a essa esfera cultural de significação relacionada a esse "outro mundo" 28 .

Levanta-se também a hipótese que o uso de raciocínios epidemiológicos espontâneos, anteriormente comentados, dever-se-ia não apenas às compreensíveis dificuldades de apropriação de conhecimentos técnicos específicos. Parece decorrer também da utilização de mecanismos psicológicos defensivos (racionalizações) decorrentes de conflitos dolorosos relacionados ao desejo de interromper o uso sem, contudo, ter como demandar tratamentos.

A partir de manifestações vindas de variadas fontes (elas próprias, suas famílias nucleares e estendidas, conhecidos, mídia e profissionais de saúde), as mulheres entrevistadas precisaram lidar com um conjunto de pressões que se configuram, na instância individual, como reforços motivacionais para rever seus padrões de uso. Alguns desses incentivos podem ser classificados como positivos (ao acentuarem os aspectos considerados bons de interromper). Porém, as entrevistadas pareceram ter valorizado emocionalmente, sobretudo, os chamados incentivos negativos (argumentos que insistiam nos vários problemas, pressões e sanções por continuar usando). À medida que não estiveram expostas a alternativas terapêuticas, elas vivenciaram sozinhas as angústias correspondentes a esses conflitos, sem perceberem reciprocidades das pessoas próximas e, menos ainda, sem perceberem que tais pressões são decorrências, ao menos parcialmente, de uma construção ideológica do papel de gênero que lhes é atribuído (devem ser "boas gestantes", "boas nutrizes", "boas mães" e, portanto, "não fumar"). Perante todo esse conjunto, a utilização de alguns mecanismos psicológicos de defesa, como a racionalização e a negação, é decorrência esperada.

\section{Ausência de uma "cultura terapêutica" para tabagismo na APS}

Em vista do exposto e discutido até aqui, considera-se não haver entre as participantes a percepção de existir uma cultura, pelo menos na APS, de demandar tratamentos para tabagismo durante a gestação, isso, apesar de as participantes terem identificado, ao que tudo indica, uma cultura de pressão para que revissem seus padrões de utilização de tabaco. A ideia de haver medidas terapêuticas eficazes não parece presente nos seus repertórios cognitivos. Tais medidas não seriam percebidas como fazendo parte do serviço de saúde que utilizam: ao contrário, constataram, na prática, a ausência de um braço tecnológico efetivo das ciências médicas e psicológicas para o manejo dessa condição de saúde, em franco contraste com as possibilidades reais que, embora poucas, são de fato existentes.

Essa ausência de percepção de canais de demandas (por exemplo, ausência de protocolos de atendimento) parece corresponder às dificuldades, no mesmo sentido, presentes no polo oposto da relação (cuidadores formais). Sabe-se que mesmo os especialistas focais que trabalham de perto com tabagistas costumam não efetivar esses cuidados ${ }^{29}$. No caso do tabagismo durante a gestação, essas dificuldades profissionais teriam suas consequências maximizadas, pois se considera que, se instituídas, as medidas terapêuticas nesse período apresentam uma ótima relação custo-benefício ${ }^{30}$.

\section{CONCLUSÕES}

Na clínica exercida a gestantes dependentes de tabaco/nicotina, sobretudo na APS/USF, os profissionais podem se defrontar com situações e relatos altamente complexos quanto aos fatores socioculturais envolvidos na gênese e manutenção desses quadros. Alguns desses fatores revelam-se diretamente envolvidos em intensos conflitos e sofrimentos emocionais dessas pacientes. Parte de suas necessidades termina por se tornar um desejo de resolução do problema, embora nem sempre, ou mesmo raramente (como no caso das participantes entrevistadas), esses desejos se tornem demandas dirigidas a cuidadores formais. Ademais, quando as demandas chegam a ser explicitadas, os clínicos não foram percebidos pelas entrevistadas como capazes de efetivar as poucas possibilidades terapêuticas existentes.

Para atender às demandas com que venham a se defrontar, os clínicos deveriam, de acordo com os atuais consensos sobre tabagismo, ser competentes quanto às técnicas de intervenções cognitivo-comportamentais, que requerem sofisticadas habilidades, em geral pouco abordadas em suas formações. Trata-se de habilidades cognitivas e afetivas que 
permitiriam o desenvolvimento de sensibilidade aos fatores socioculturais relacionados ao hábito tabágico entre as gestantes e às suas dificuldades em lidar com o problema. Isso incluiria o enfrentamento que fazem das desigualdades de gênero, agravadas por condições socioeconômicas por vezes também de grande relevância, como costuma ser o caso das mulheres hoje atendidas na APS, pertencentes aos estratos socioeconômicos mais baixos da população.

É de se salientar, entretanto, que as gestantes entrevistadas não se sentiram alvos de qualquer tipo de intervenção motivacional ou terapêutica sistemática, inclusive daquelas que correspondessem unicamente ao modelo biomédico, já reconhecidamente limitado, particularmente para a população de gestantes.

Estudos qualitativos, como este, complementam os conhecimentos advindos de estudos de epidemiologia clínica e populacional sobre o tabagismo na gestação, possibilitando um aprofundamento na compreensão dos significados pessoais e culturais dessas ocorrências. Caso considerados clinicamente válidos pelos leitores, os resultados podem subsidiar suas reflexões clínicas e suas condutas acerca das práticas de aconselhamento e de intervenção motivacional. Noutros termos, conhecer as perspectivas das mulheres gestantes tabagistas entrevistadas pode favorecer a competência cultural dos profissionais diante dessa problemática, sobretudo no dia a dia dos serviços de APS e ao lidar com pacientes de estratos socioeconômicos próximos aos do conjunto de mulheres aqui estudado.

Não foi objetivo do estudo, e não seria possível metodologicamente, considerar as categorias formuladas como generalizáveis para toda a população de gestantes fumantes. Essa validade externa dos achados só pode ser avaliada pelos próprios leitores, diante a suas próprias pacientes.

\section{REFERÊNCIAS}

1. US Department of Health and Human Services. The health consequences of smoking: a report of the Surgeon General. Washington DC: US Government Printing Office; 2004.

2. World Health Organization. Tobacco and poverty: a vicious circle. Geneva: WHO; 2004

3. Carlini EA, Galduróz JCF, Noto AR, Nappo SA. I Levantamento domiciliar sobre o uso de drogas psicotrópicas no Brasil: estudo envolvendo as 107 maiores cidades do país: 2001. São Paulo: CEBRID/UNIFESP; 2002.

4. Carlini EA, Galduróz JC, Silva AAB, Noto AR, Fonseca AM, Carlini CM, et al. II Levantamento domiciliar sobre o uso de drogas psicotrópicas no Brasil: estudo envolvendo as 108 maiores cidades do país: 2005. São Paulo: Cebrid - Centro Brasileiro de Informação sobre Drogas Psicotrópicas/Unifesp - Universidade Federal de São Paulo; 2006.

5. Brasil. Ministério da Saúde. Secretaria de Vigilância em Saúde. Secretaria de Atenção à Saúde. Política nacional de promoção da saúde. Brasília: Ministério da Saúde; 2006.
6. Brasil. Ministério da Saúde. Instituto Nacional de Câncer. Coordenação de Prevenção e Vigilância. Abordagem e tratamento do fumante - Consenso 2001. Rio de Janeiro: INCA; 2001.

7. Zaleski M, Laranjeira RR, Marques ACPR, Ratto L, Romano M, Alves HNP, et al. Diretrizes da Associação Brasileira de Estudos do Álcool e outras Drogas (ABEAD) para o diagnóstico e tratamento de comorbidades psiquiátricas e dependência de álcool e outras substâncias. Rev Bras Psiquiatr. 2006;28:142-8.

8. Reichert J, Araújo AJD, Gonçalves CMC, Godoy I, Chatkin JM, Sales MDPU, et al. Diretrizes para cessação do tabagismo - 2008. Smoking cessation guidelines - 2008. J Bras Pneumol. 2008;34:845-80.

9. Cnattingius $S$. The epidemiology of smoking during pregnancy: smoking prevalence, maternal characteristics, and pregnancy outcomes. Nicotine Tob Res. 2004;6:S125-40.

10. Marin GH, Delgado L, Sager G, Visentín S, Azzaro S, Tozzi M. Consequences of smoking during pregnancy for mother and child. Rev Bras Saude Mater Infant. 2003;3:159-64.

11. Rozov T, Fiss E, Catherino P, Perestrelo MI, Nomura M. Hábito de fumar das gestantes e parturientes de um hospital universitário e seus conhecimentos sobre os efeitos do fumo em fetos e lactentes. Arq Med ABC. 2004;29:28-36.

12. Solomon L, Quinn V. Spontaneous quitting: self-initiated smoking cessation in early pregnancy. Nicotine Tob Res. 2004;6:S203-16.

13. Reis $L G$, Silva CJD, Trindade A, Abrahão M, Silva VAD. Women who smoke and stop during pregnancy: who are they? Rev Bras Saude Mater Infant. 2008;8:217-21.

14. Kroeff $L R$, Mengue SS, Schmidt MI, Duncan BB, Favaretto ALF, Nucci LB. [Correlates of smoking in pregnant women in six Brazilian cities]. Rev Saude Publica. 2004;38:261-7.

15. Borges MTT, Simões-Barbosa RH. Cigarro "companheiro": o tabagismo feminino em uma abordagem crítica de gênero. Cad Saude Publica. 2008;24:2834-42.

16. Borges MTT, Barbosa RHS. As marcas de gênero no fumar feminino: uma aproximação sociológica do tabagismo em mulheres. Ciênc Saúde Coletiva. 2009;14:1129-39.

17. Possato M, Parada CMGDL, Tonete VLP. Representação de gestantes tabagistas sobre 0 uso do cigarro: estudo realizado em hospital do interior paulista. Rev Esc Enferm USP. 2007:41:434-40.

18. Boltanski L. As classes sociais e o corpo. $4^{\mathrm{a}}$ ed. São Paulo: Graal; 2004.

19. Helman CG. Cultura, saúde e doença. $4^{a}$ ed. Porto Alegre: Artmed; 2003.

20. Moscovici S. A representação social da psicanálise. 2a ed. Rio de Janeiro: Zahar; 1978.

21. Herzlich C. A problemática da representação social e sua utilidade no campo da doença. Physis. 2005;15:57-70

22. Fontanella BJB, Campos CJG, Turato ER. Data collection in clinical-qualitative research: use of nondirected interviews with open-ended questions by health professionals. Rev Lat Am Enfermagem. 2006;14:812-20.

23. Jovchelovitch S, Bauer MW. Entrevista narrativa. In: Bauer MW, Gaskell G, organizadores. Pesquisa qualitativa com texto, imagem e som: um manual prático. Petrópolis: Vozes; 2002. p. 90-113.

24. Bardin L. Análise de conteúdo. Lisboa: Edições 70; 1979.

25. Glaser $G$, Strauss A. The discovery of grounded theory: strategies for qualitative research. New York: Aldine de Gruyter; 1967.

26. Fontanella BJB, Ricas J, Turato ER. Amostragem por saturação em pesquisas qualitativas em saúde: contribuiç̧ões teóricas. Cad Saude Publica. 2008;24:17-27.

27. Fontanella BJB, Turato ER. Spontaneous harm reduction: a barrier for substance-dependent individuals seeking treatment? Rev Bras Psiquiatr. 2005;27:272-7.

28. Da Matta R. A casa e a rua. Rio de Janeiro: Guanabara-Koogan; 1991.

29. Viegas CADA, Valentim AGT, Amoras JAP, Nascimento EJM. Atitudes dos pneumologistas brasileiros em face da dependência de nicotina: inquérito nacional. J Bras Pneumol. 2010;36:239-42.

30. Leopércio W, Gigliotti A. Tabagismo e suas peculiaridades durante a gestação: uma revisão crítica. J Bras Pneumol. 2004;30:176-85. 